\title{
Positioning Embedded Software Maintenance within Industrial Maintenance
}

\author{
Ramin Karim \\ Div. of Operation \& Maintenance \\ Luleå University of Technology \\ ramin.karim@ltu.se
Olov Candell, Tommy Tyrberg
Saab Aerotech
olov.candell@saabgroup.com
tommy.tyrberg@saabgroup.com

\author{
Mira Kajko-Mattsson \\ $D S V$ \\ Stockholm University and KTH \\ mira@dsv.su.se \\ Hans Öhlund \\ Swedish Air Force Wing F21 \\ hans.ohlund@mil.se
}

\author{
Peter Söderholm \\ Div. of Operation \& Maintenance \\ Luleå University of Technology \\ peter.soderholm@ltu.se \\ Jan Johansson \\ Swedish Defence Materiel Adm. \\ jan.h.johansson@postbox.mil.se
}

\begin{abstract}
Little is known about of how software embedded in complex industrial technical systems is maintained. In this paper, we identify industrial maintenance process steps and position software maintenance activities within them. We do this in the context of JAS 39 Gripen, a multi-role combat aircraft developed by Saab.
\end{abstract}

\section{Introduction}

Complex industrial technical systems consist of both hardware and software components. Examples of such systems can be found within the aerospace, power generation, railway and process industries. One of their main characteristics is that their software components are embedded in their respective hardware components.

Substantial research has been carried out to discover ways to support and maintain either software or hardware products. However, less effort has been spent on finding out how these two disciplines co-exist, i.e. to identify their common points of contact.

This paper is one result of a joint research project between the aerospace industry and academia in Sweden. It presents a study performed in co-operation with Saab Aerotech [1], the Swedish Air Force Wing F21 [2] and the Swedish Defence Materiel Administration (FMV) [3]. It identifies industrial maintenance process steps and positions software maintenance within them. By industrial maintenance, we mean a combination of all technical and administrative actions, including supervision, intended to retain an item in, or restore it to a state in which it can perform a required function $[4,5]$.
The remainder of this paper is as follows. Section 2 describes our research methodology. Section 3 briefly presents the studied product and the involved organizations. Section 4 describes the structure of complex technical systems and positions software within them. Section 5 describes a generic industrial maintenance process, whereas Section 6 describes the maintenance process of JAS 39 Gripen. Finally, Section 7 presents some conclusions.

\section{Methodology}

As a first step, we studied documentation provided by Saab, F21 and FMV. We also made a series of interviews with system technicians, maintenance technicians, maintenance managers, software developers and project managers. Our goal was to learn about the overall maintenance of the aircraft.

This step resulted in the identification of maintenance echelons and major industrial maintenance process phases. To gain a deeper understanding of the process, we then organized a workshop together with representatives from Saab, F21 and FMV. These representatives are the co-authors of this paper. Altogether, eight people were engaged in the workshop: three academics, two suppliers and two customer representatives and one moderator.

During the workshop, we discussed the overall industrial maintenance process. Our goal was twofold: to find out (1) how aircraft items are maintained, and (2) how their embedded software components are handled in each respective industrial maintenance phase. The outcome of the workshop has been documented and sent for verification. It is this outcome that is presented in this paper. 


\section{Product and Parties Involved}

Gripen is a multi-role combat aircraft that can perform three missions: interception, air-to-ground and reconnaissance. It has been developed by the Swedish company Saab. It is operated by nations such as the Czech Republic, Hungary, South Africa, Thailand and Sweden. In Sweden, its customer representative is FMV and the operator is the Swedish Air Force.

Saab's role is to provide maintenance guidelines and in-service-support to its customers and the aircraft users, and to perform highly specialized maintenance and modifications. In the Swedish case, FMV's role is to adapt Saab's guidelines to the user's organizational context. The Swedish Air Force's role is to operate and maintain the aircraft according to Saab and FMV's guidelines. These roles and responsibilities are similar for all nations operating the aircraft.

\section{Maintained Items}

Products such as a combat aircraft are complex technical systems. They have very intricate configurations. As illustrated in Figure 1, they can be structured in a hierarchy of items, called indenture levels. These levels describe the system's inherent items and identify the items' relative complexity as an assembly or function. Within industrial maintenance, the main usage of indenture levels it to prescribe related maintenance tasks.

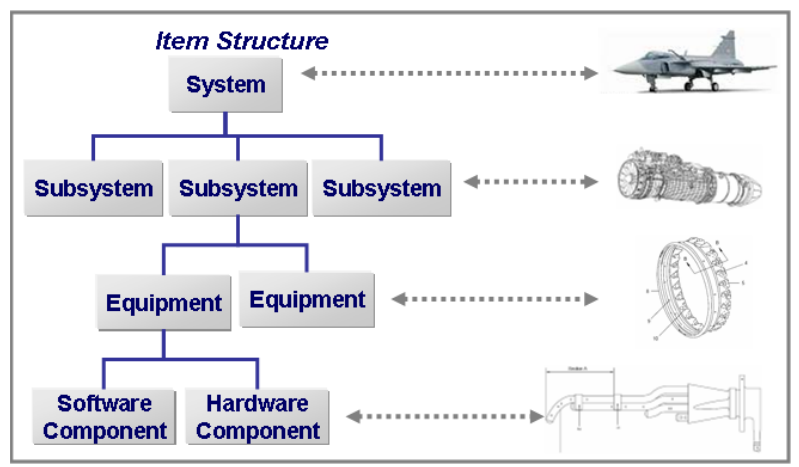

Figure 1. Indenture levels of a system

As illustrated in Figure 1, the aircraft is on the $1^{\text {st }}$ indenture level. Its subsystems, e.g. the engine, are placed on the $2^{\text {nd }}$ level. The engine's constituents, e.g. the spraybar slots, are placed on the $3^{\text {rd }}$ level. Finally, the spraybars are on the lowest level.

Another way of looking at items from a maintenance perspective is illustrated in Figure 2. Here, the items are classified as Line Replaceable Units (LRUs) or Shop Replaceable Units (SRUs).

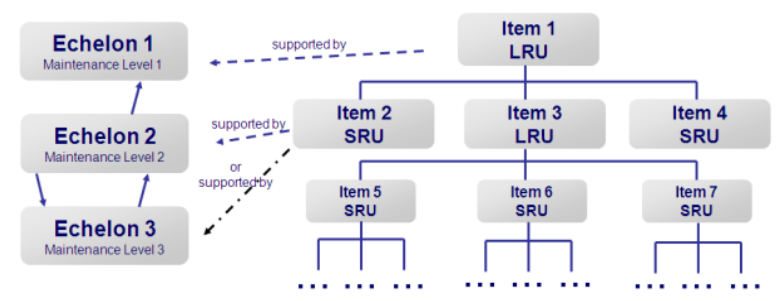

Figure 2. Structure of maintenance items, the echelons, and the relationship between them

From an industrial maintenance perspective, this classification indicates the way these items are maintained. Both LRUS and SRUS may consist of hardware and software components.

A prevalent solution within aircraft maintenance is to use three maintenance echelons, although other solutions also exist. The LRUs are removed and replaced at the deployed site of the system, for instance, in the field (i.e. Echelon 1). By doing this, one restores the parent item to an operational condition. The SRUs, on the other hand, are only attended to at a shop level (i.e. Echelons 1 and 2). To attend to a faulty $S R U$, one must first remove its closest $L R U$ parent, and take it to a shop, where a technician gets inside it to remove the faulty $S R U$.

\section{Industrial Maintenance Process}

An industrial maintenance process covers a spectrum of activities required for managing, planning, preparing, executing, assessing and improving maintenance. These activities are described in Section 6. They involve a wide range of roles, such as managers, process owners, maintenance technicians, maintenance planners and logistic managers.

Within industrial maintenance, there are two main maintenance strategies: preventive and corrective. Preventive Maintenance $(P M)$ implies proactive changes made to a system to avoid possible future problems. Corrective Maintenance $(C M)$, on the other hand, implies reactive changes performed to correct faults. The selection between PM and CM mainly depends on the criticality of the maintained item.

Industrial maintenance execution is organized in echelons [5], while its support is organized in support lines similar to those described in [6]. A maintenance echelon is an organizational level where a specified set of maintenance actions are carried out on an item [4, 5]. An example of a specific maintenance action is the replacement of an $L R U$. The left side of Figure 2 depicts the echelons. A support line, on the other hand, is an organizational level where specific support is provided to a customer. An example of a support task 
is the provision of advice on how to execute a maintenance task at an echelon.

\section{Maintenance of JAS 39 Gripen}

In this section, we present the overall industrial maintenance process related to Gripen. We describe how maintenance is managed across the echelons in Section 6.1 and across the maintenance phases in Section 6.2. We also position maintenance of embedded software components within those two.

\subsection{Echelons}

Gripen is managed across three echelons. Maintenance at Echelon 1 is conducted at an operator level in the field. Here, maintenance is conducted at predetermined intervals (PM) or after having experienced a failure (CM). Due to the fact that the tasks performed at this level are less complicated, they are conducted directly on the aircraft. These tasks include aircraft inspections, adjustments, calibration, cleaning, lubrication, repair and replacement of LRUs. Regarding the embedded software, it is managed like any hardware component at this level. This means that its hosting non-functioning $L R U$ gets replaced with a functioning $L R U$. The removed $L R U$ is then sent for repair at another echelon. It is also praxis to upload software upgrades into the aircraft at Echelon 1.

At Echelon 2, more qualified tasks are performed mainly off-aircraft, in maintenance shops. Examples of tasks are removal and replacement of faulty $S R U \mathrm{~s}$, repair of breaks and pilot safety equipment. Here, one may discover software problems in $L R U s$ received from Echelon 1. If such is the case, one reports on these software problems to Saab.

Maintenance at Echelon 3 is performed by Saab, its suppliers or a third party. Here, highly specialized personnel overhaul items and major assemblies, such as aircraft engines. Echelon 3 is also central for coordination of maintenance support planning, assessment and improvement.

As indicated above, embedded software maintenance covers a broad spectrum of activities, spanning from the resetting of processing units in an operational environment (Echelon 1) to debugging, tracing and testing of source code in a test environment at the industry (Echelon 3).

\subsection{Maintenance Process}

The process of maintaining Gripen consists of the six phases: Maintenance Management, Maintenance Support Planning, Maintenance Preparation,
Maintenance Execution, Maintenance Assessment and Maintenance Improvement. These process phases and the documents managed within them are illustrated in Figure 3.

The first phase, Maintenance Management, is conducted by Saab, FMV, as well as certification and legal authorities. Using rules, directives, and requirements defined by $\mathrm{Saab}$ in the Maintenance Program, FMV provides an operator specific Aircraft Maintenance Plan defining guidelines and directives for how the Swedish Air Force should maintain their Gripen fleet. The contents of the Aircraft Maintenance Plan should apply to the whole aircraft lifecycle. It may however be changed in cases when modifications are done to either the aircraft or the maintenance policies. The items to be maintained are defined as functional units. In this phase, software components are not distinguished from other components. They are treated under the umbrella of various functional items.

The Maintenance Support Planning phase is conducted by the Swedish Air Force's Fleet Management Office (FMO). The FMO produces a Fleet Maintenance Plan defining maintenance of their whole aircraft population. It also creates plans for maintaining individual aircraft. These plans are called Individual Maintenance Plans. Both plans include the identification and planning of spare parts, personnel and their competence level, tools, LRUs/SRUs, and the like. They are based on historical data and experiences as recorded in the Historical Data \& Experience documents, and the like. In this phase, software components are treated under the umbrella of various functional items.

The Maintenance Preparation phase is conducted at all echelons. It manages both planned and unplanned tasks. The planned ones concern preventive tasks to be conducted at predetermined time intervals (i.e. PM). The unplanned ones, on the other hand, are corrective tasks in response to failure recognition (i.e. CM). The outcome of this phase is a Maintenance Work Order (MWO) specifying the tasks and required resources. In this phase, software components are treated under the umbrella of various functional items. However, the $M W O$ may also explicitly define tasks regarding software upgrades.

The Maintenance Execution phase is conducted on Echelon 1 and 2 by the Swedish Air Force and on Echelon 3 by the industry. The goal is to keep the aircraft in an airworthy condition. The technicians perform maintenance tasks as designated in the $M W O$. Some results generated during and after this phase are, e.g. Technical Report (TR), Action Report (AR) and Change Request (CR). The TR gives an account of problems encountered during the Maintenance Execution phase. 


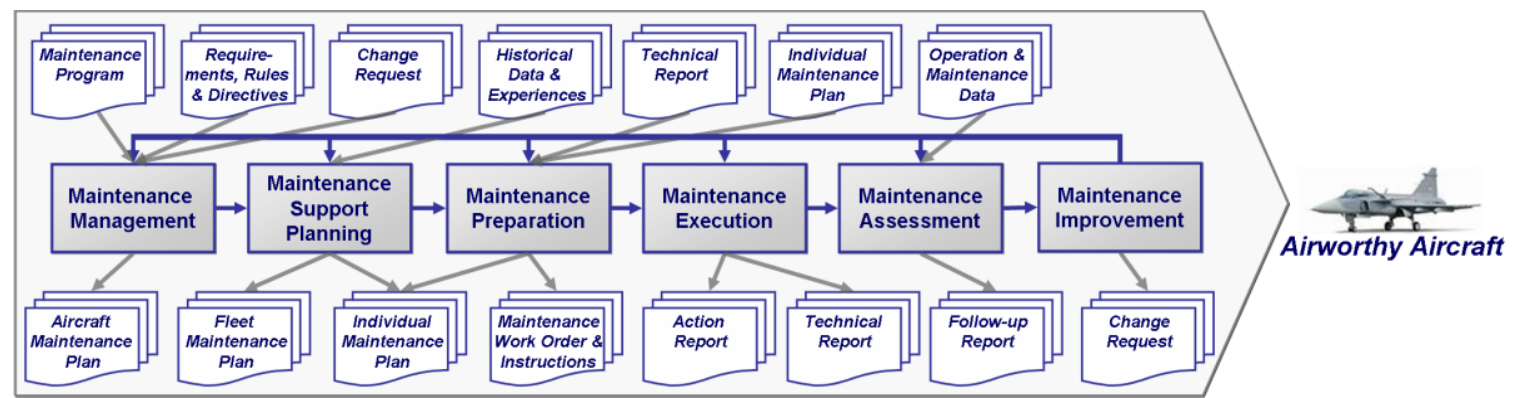

Figure 3. Example of aircraft maintenance process

The $A R$ records the performed maintenance tasks and the list of removed items sent to other echelons. The $C R$ suggests major changes to aircraft design, maintenance program and/or plan. In this phase, software is treated just like any other type of item. This concerns both its removal and installation. For instance, when replacing the faulty $L R U$, one is not aware of whether its faulty component is software or hardware. One simply sends the faulty $L R U$ to Echelon 2 or 3 . If one identifies a software problem on any echelon, then one reports it to the industry (Saab or its suppliers). The industry then corrects the software fault. In this phase, one may also upgrade embedded (on-board) software using the assistance of Ground Support Equipment (GSE), a tool used for installing software. Some minor adjustments of embedded software parameters are also conducted in this phase, e.g. contrast adjustment of head-up display and securing weapon system during a turn-around.

The Maintenance Assessment phase is conducted on Echelons 1, 2 and 3 by all the three organizations involved within maintenance plus subcontractor organizations. It takes place after the Maintenance Execution phase to ensure that the required function has been retained or restored. Its role is to assess the data collected during operation and maintenance in order to check if stated requirements are fulfilled and to make suggestions for improvements. These suggestions provide input to the Maintenance Improvement phase. In this phase, software is treated like any other type of item.

The next phase, Maintenance Improvement, is conducted on Echelons 1, 2 and 3 by Saab, FMV and the Swedish Air Force. During this phase, the improvements related to the maintenance process and working patterns are performed. Improvements related to the aircraft design and surrounding environments are reported in Change Requests and submitted to the Maintenance Management phase. In this phase, software is treated just like any other type of item.

\section{Conclusions}

This paper presents an industrial process model used for maintaining a military aircraft, Saab JAS 39 Gripen, and positions embedded software maintenance within it. It can be concluded that all maintenance activities are considered from the holistic perspective of the aircraft's functionality. The reason is that the maintenance actions are intended to retain and restore the functions that are required to keep the aircraft in an airworthy condition. Hence, the industrial maintenance process does not distinguish between hardware and embedded software components.

\section{Acknowledgements}

We thank Saab Aerotech and the Swedish National Aeronautical Research Program (NFFP) for supporting this work intellectually and financially. We would also like to thank Professor Uday Kumar for his valuable comments.

\section{References}

[1] Saab, Available on: http://www.Saabgroup.com, 2008.

[2] F21, Swedish Airforce Norrbotten Wing (F21), Available on: http://www.f21.mil.sel, 2008.

[3] FMV, Swedish Defence Materiel Administration, Available on: http://www.fmv.se/, 2008.

[4] IEC, International Electrotechnical Commission "Electropedia", Available on: http://www.electropedia.org/, 2008.

[5] IEC-60300-3-14, "Dependability management, Part 314: Application guide; Maintenance and maintenance support", IEC, Geneva, Switzerland, 2004.

[6] Kajko-Mattsson. M, Maturity Status within Front-End Support Organisations, International Conference on Software Engineering, IEEE, 2007. 